\title{
Experimental validation of calculated atomic charges in ionic liquids
}

Richard M. Fogarty, Richard P. Matthews, Claire R. Ashworth, Agnieszka Brandt-Talbot, Robert G. Palgrave, Richard A. Bourne, Tom Vander Hoogerstraete, Patricia A. Hunt, and Kevin R. J. Lovelock

Citation: The Journal of Chemical Physics 148, 193817 (2018); doi: 10.1063/1.5011662

View online: https://doi.org/10.1063/1.5011662

View Table of Contents: http://aip.scitation.org/toc/jcp/148/19

Published by the American Institute of Physics

\section{Articles you may be interested in}

Focus Article: Oscillatory and long-range monotonic exponential decays of electrostatic interactions in ionic liquids and other electrolytes: The significance of dielectric permittivity and renormalized charges

The Journal of Chemical Physics 148, 193701 (2018); 10.1063/1.5010024

Mechanical heterogeneity in ionic liquids

The Journal of Chemical Physics 148, 193803 (2018); 10.1063/1.5008752

Cluster approach to the prediction of thermodynamic and transport properties of ionic liquids

The Journal of Chemical Physics 148, 193832 (2018); 10.1063/1.5009791

Preface: Special Topic on Chemical Physics of lonic Liquids

The Journal of Chemical Physics 148, 193501 (2018); 10.1063/1.5039492

Change of hydrogen bonding structure in ionic liquid mixtures by anion type

The Journal of Chemical Physics 148, 193827 (2018); 10.1063/1.5010067

Dynamical heterogeneities of rotational motion in room temperature ionic liquids evidenced by molecular dynamics simulations

The Journal of Chemical Physics 148, 193811 (2018); 10.1063/1.5005143

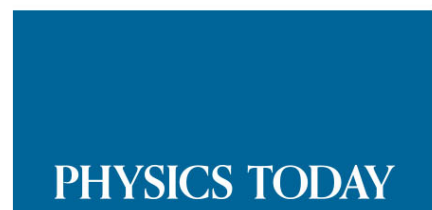

WHITEPAPERS
ADVANCED LIGHT CURE ADHESIVES

Take a closer look at what these environmentally friendly adhesive systems can do
READ NOW

PRESENTED BY

(8) MASTERBOND० 


\title{
Experimental validation of calculated atomic charges in ionic liquids
}

\author{
Richard M. Fogarty,${ }^{1}$ Richard P. Matthews, ${ }^{1}$ Claire R. Ashworth, ${ }^{1}$ Agnieszka Brandt-Talbot, ${ }^{2}$ \\ Robert G. Palgrave, ${ }^{3}$ Richard A. Bourne,${ }^{4}$ Tom Vander Hoogerstraete, ${ }^{5}$ Patricia A. Hunt, ${ }^{1, a)}$ \\ and Kevin R. J. Lovelock ${ }^{6, a)}$ \\ ${ }^{1}$ Department of Chemistry, Imperial College London, London, United Kingdom \\ ${ }^{2}$ Department of Chemical Engineering, Imperial College London, London, United Kingdom \\ ${ }^{3}$ Department of Chemistry, University College London, London, United Kingdom \\ ${ }^{4}$ School of Chemical and Process Engineering and Institute of Process Research and Development, \\ School of Chemistry, University of Leeds, Leeds, United Kingdom \\ ${ }^{5}$ Department of Chemistry, KU Leuven, Leuven, Belgium \\ ${ }^{6}$ Department of Chemistry, University of Reading, Reading, United Kingdom
}

(Received 1 November 2017; accepted 29 December 2017; published online 7 February 2018)

\begin{abstract}
A combination of X-ray photoelectron spectroscopy and near edge X-ray absorption fine structure spectroscopy has been used to provide an experimental measure of nitrogen atomic charges in nine ionic liquids (ILs). These experimental results are used to validate charges calculated with three computational methods: charges from electrostatic potentials using a grid-based method (ChelpG), natural bond orbital population analysis, and the atoms in molecules approach. By combining these results with those from a previous study on sulfur, we find that ChelpG charges provide the best description of the charge distribution in ILs. However, we find that ChelpG charges can lead to significant conformational dependence and therefore advise that small differences in ChelpG charges $(<0.3 e)$ should be interpreted with care. We use these validated charges to provide physical insight into nitrogen atomic charges for the ILs probed. Published by AIP Publishing. https://doi.org/10.1063/1.5011662
\end{abstract}

\section{INTRODUCTION}

Ionic liquids (ILs) are liquids composed solely of mobile cations and anions. ILs are promising materials for a wide range of applications: solvents for catalysis; ${ }^{1}$ electrolytes for electrodeposition, batteries, and supercapacitors; ${ }^{2-5}$ materials for gas separation and storage; $;, 7$ and solvents for nuclear fuel reprocessing. ${ }^{8}$ However, the full potential of ILs is currently unrealised, partly owing to the lack of understanding between how varying molecular properties (i.e., the chemical nature of the constituent ions) affects macroscopic properties (i.e., viscosity). In this paper, we aim to gain a better understanding of how to represent the charge distribution of individual ions in ILs.

Almost all ILs are composed of molecular (or atomic) ions with an overall formal charge of \pm 1 (there are some ILs formed from ions with \pm 2 charge). Thus, the primary factor that differentiates ILs from each other is not the overall charge of individual ions; differences between ILs must be dependent on the charge distribution. There are two ways to describe variation in charge distribution for ILs: (i) differences in how the charge is distributed within a particular ion and (ii) transfer of charge from the anion to the cation (i.e., non-integer values of total ion charge).

Results from molecular dynamics (MD) simulations have shown that even quite subtle differences in the charge distribution in an IL can strongly affect macroscopic properties of the

a)Authors to whom correspondence should be addressed: k.r.j.lovelock@ reading.ac.uk and p.hunt@imperial.ac.uk
IL. ${ }^{9-17}$ Varying the charge distribution within each ion, while keeping a $\pm 1 e$ charge on each ion, can significantly affect dynamic properties. For example, Li and Kobrak compared MD simulations using octahedral ions with either a symmetric (charge spread equally over the ion) or a non-symmetric (charge localised on one half of the ion) charge distribution. ${ }^{9}$ The symmetric, compared to non-symmetric, charge distribution led to significantly slower diffusion but faster rotational dynamics. ${ }^{9}$ Multiple other MD studies have found that varying the charge distribution can lead to significant changes in predicted structural, dynamic, or energetic properties. ${ }^{10-17}$ Therefore, understanding the charge distribution within ILs is key to linking IL composition with macroscopic physical properties.

Charge distribution is often represented in terms of atomic charges. The atomic charge of atom $\mathrm{A}, q(\mathrm{~A})$, is defined as $q(\mathrm{~A})=Z_{\mathrm{A}}-\rho_{\mathrm{A}}$, where $Z_{\mathrm{A}}$ is the atomic number of $\mathrm{A}$ and $\rho_{\mathrm{A}}$ is the total electron density assigned to A. The density at any point in space, $\rho(\mathrm{r})$, is an observable property; however, there is no unambiguous way to partition this density between atomic centres (i.e., $\rho_{\mathrm{A}}$ cannot be determined unambiguously). As a result, a range of methods exist for determining $\rho_{\mathrm{A}}$ [and hence, $\left.q(\mathrm{~A})\right]$. The majority of $q(\mathrm{~A})$ assignment methods fall into one of the three categories: density-based, wavefunction-based, or electrostatic potential (ESP)-based methods.

The "Atoms in Molecules" (AIM) approach involves the direct analysis of the topology of the electron density. ${ }^{18,19}$ Around each nucleus exists a surface for which the flux of the electron density gradient field is zero. These surfaces are used to partition a system into a set of nuclear basins. AIM $q(\mathrm{~A})$ are 
obtained by assigning all electron density in a nuclear basin to the relevant nucleus. AIM $q(\mathrm{~A})$ are known to be significantly larger in magnitude than those produced by other methods, either wavefunction-based or ESP-based..$^{20,21}$

Wavefunction (or population analysis) methods require the electron density to be expanded in terms of a basis set; often the atomic orbitals (AOs) form the basis functions. The electron density is then divided among the basis orbitals; the exact procedure varies between methods. Electron density is subsequently assigned to the atom on which the basis orbital is centred, and summing over the density in each basis orbital enables $q(\mathrm{~A})$ to be calculated. A problem is that some population analysis methods (e.g., Mulliken) can show a strong basis set dependence. ${ }^{22}$ The population analysis method used in the current work, natural bond orbital (NBO) analysis, reduces the basis-set dependence by expressing the density in terms of natural orbitals, which are localised AOs for a particular molecular environment. ${ }^{23,24}$ Wavefunction methods of this type are inherently local, tied to the atomic centre, and are not strongly influenced by charge distributions outside of the atomic region. We call charges derived from NBO analysis "NBO charges" (Natural Population Analysis, NPA, charges is an equivalent name); these charges are known to overestimate the magnitude of the $\mathrm{ESP},{ }^{20}$ but to a lesser extent when compared with AIM.

The first step in ESP methods is to calculate the ESP (using the total electron density and nuclear co-ordinates) at a range of points - we will label this $\mathrm{ESP}_{\text {ed }}$. A second ESP $\left(\mathrm{ESP}_{\mathrm{pc}}\right)$ is then calculated at each point using solely a set of point charges centred at each nucleus, $q(\mathrm{~A}), q(\mathrm{~A})$ are subsequently varied to minimise the difference between $\mathrm{ESP}_{\mathrm{ed}}$ and $\mathrm{ESP}_{\mathrm{pc}}$. Thus, the calculated $q(\mathrm{~A})$ are those that best reproduce the true ESP of the system. Different ESP methods vary mainly in the selection of fitting points; for example, a rectangular grid of points is used in the "charges from electrostatic potential using a grid-based method" (ChelpG) that is used in the current work. ${ }^{25}$ The fitting points for ESP methods are generally reasonably far from any nuclei (a distance of 1-1.4 times the van der Waals radius). This results in the problem of "buried charges" for ESP methods. ${ }^{26,27} \mathrm{ESP}_{\mathrm{pc}}$ is much less sensitive to varying $q(\mathrm{~A})$ for a buried atom than an exposed one; hence, $q(\mathrm{~A})$ on a buried atom is said to be poorly determined and care should be taken when interpreting such data. ${ }^{26}$

$q(\mathrm{~A})$ are mathematical constructs, not inherent physical quantities; thus, $q(\mathrm{~A})$ cannot be directly experimentally measured. The results of each $q(\mathrm{~A})$ assignment method are termed "charges". However, each method describes something slightly different. Thus, $q(\mathrm{~A})$ from each method should not be thought of as identical, despite the common terminology generally used. Different $q(\mathrm{~A})$ assignment methods can lead to qualitatively different charge distributions for ILs. For example, the nitrogen atomic charge, $q(\mathrm{~N})$, in $\left[\mathrm{C}_{4} \mathrm{C}_{1} \mathrm{Im}\right] \mathrm{Cl}$ (1-butyl-3-methylimidazolium chloride) was calculated as $q(\mathrm{~N})=-0.3 e$ using $\mathrm{NBO}$ and as $q(\mathrm{~N})=+0.1 e$ using ChelpG. ${ }^{11,28}$ The ChelpG $q(\mathrm{~N})$ suggests that the anion will be electrostatically attracted to the nitrogen atom in $\left[\mathrm{C}_{4} \mathrm{C}_{1} \mathrm{Im}\right]^{+}$, whereas the $\mathrm{NBO} q(\mathrm{~N})$ suggests that the anion will be repelled from the cationic nitrogen. The NBO $q(\mathrm{~N})$ is consistent with nitrogen being an electronegative atom, whereas the ChelpG $q(\mathrm{~N})$ is not. The qualitatively different conclusions that can be drawn from NBO and ESP methods demonstrate the importance of understanding the kind of information each "charge" delivers. The qualitative differences are unsurprising, given that electron density and wavefunction methods are based on the electron density (mostly) within the van der Waals radii of atomic centres, whereas ESP methods are based on the ESP outside this region, i.e., not only are different quantities being examined but they are also being evaluated in orthogonal spatial regions. No $q(A)$ method adequately addresses issues relating to anisotropic electron density or ESP distributions. A point charge is a spherically isotropic entity; it cannot easily represent situations in which the charge density varies rapidly or the ESP is better represented by a local dipole or quadrupole. There has now been substantial work carried out to examine higher multipoles, both for ESP and density-derived charges. ${ }^{29-31}$ Nevertheless, $q(\mathrm{~A})$ are frequently used in MD simulations to interpret the electronic structure and to understand electrostatic interactions. From this perspective, it is extremely valuable to find which $q(\mathrm{~A})$ assignment method best correlates with experimental values that approximate $q(\mathrm{~A})$.

Both X-ray photoelectron spectroscopy (XPS) and near edge X-ray absorption fine structure (NEXAFS) spectroscopy can provide indirect yet separate measures of $q(\mathrm{~A})$. To obtain an indirect experimental measure of $q(\mathrm{~N})$, the ground state of ILs need to be probed, i.e., initial state effects. However, experiments always include some contribution from the excited state, i.e., final state effects. Therefore, the potential contributions of initial and final state effects to XPS and NEXAFS spectroscopy must be considered; these effects are different for the two techniques, meaning that trends across the same sample set do not always match..$^{21,32,33}$ We have previously demonstrated that XPS and NEXAFS spectroscopy should be used as complimentary techniques for probing $q(\mathrm{~A}) .{ }^{21}$ XPS is the best for detecting relatively large differences in $q(\mathrm{~A})$ between structurally diverse systems, whereas NEXAFS spectroscopy is the best for detecting relatively small differences in $q(\mathrm{~A})$ between structurally very similar systems. ${ }^{21}$

Experimental core orbital electron binding energies, $E_{\mathrm{B}}$, measured using XPS represent the energy required to remove an electron from an orbital, i.e., the negative of the orbital energy; more stable orbitals have larger $E_{\mathrm{B}}$. Core orbital $E_{\mathrm{B}}$ values mainly depend on the element and type of orbital (e.g., C 1s orbitals have $E_{\mathrm{B}} \sim 280 \mathrm{eV}$ ), but the local atomic environment can cause (relatively) small $E_{\mathrm{B}}$ shifts. For example, the $\mathrm{C} 1 \mathrm{~s} E_{\mathrm{B}}$ for the alkyl chain carbon atoms of $\left[\mathrm{C}_{8} \mathrm{C}_{1} \mathrm{Im}\right]^{+}$is $E_{\mathrm{B}}=285.0 \mathrm{eV}$ compared with $E_{\mathrm{B}}=292.9 \mathrm{eV}$ for carbon in $\left[\mathrm{NTf}_{2}\right]^{-}\left(-\mathrm{CF}_{3}\right.$ group) ${ }^{34}$ The $E_{\mathrm{B}}$ difference arises because the $-\mathrm{CF}_{3}$ carbon has less electron density near its nucleus than the alkyl carbon (hence, the $-\mathrm{CF}_{3}$ carbon can be thought of as more positively charged). In general, larger $E_{\mathrm{B}}$ corresponds to a more positively charged atom. This statement is supported by previous studies correlating $E_{\mathrm{B}}$ values with calculated charges for carbon, boron, nitrogen, and sulfur atoms. ${ }^{21,35-40}$ Furthermore, $E_{\mathrm{B}}$ shifts between ILs are routinely interpreted in terms of $q(\mathrm{~A}){ }^{41-49}$ However, $E_{\mathrm{B}}$ also depends on the ability of the system to stabilise the core-hole following electron removal; this effect is independent of the ground state $q(\mathrm{~A})$ 


$\mathrm{S=C=N^{ \ominus }}$

FIG. 1. Structures and abbreviations for all ions (except $\mathrm{Cl}^{-}$) used in this study. and is termed a final state effect. We have previously suggested that, owing to final state effects, differences in $E_{\mathrm{B}}<0.5 \mathrm{eV}$ should not be interpreted in terms of $q(\mathrm{~A})$ (based on final state effects measured with Auger spectroscopy for sulfur atoms in ILs). ${ }^{21}$

NEXAFS spectroscopy involves measuring the energy required to excite a core electron into unoccupied molecular orbitals (UMOs). The lowest energy core $\rightarrow$ UMO transition observed (for a given atom) is labeled the edge energy $\left(E_{\text {NEXAFS }}\right) . E_{\text {NEXAFS }}$ is commonly interpreted in terms of oxidation state, with a larger $E_{\mathrm{NEXAFS}}$ corresponding to a higher oxidation state [hence, more positive $q(\mathrm{~A})]^{50-55}$ The electron is not removed from the sample in NEXAFS spectroscopy (whereas the electron is removed from the sample in XPS). Therefore, final state effects for NEXAFS spectroscopy are generally smaller than those for XPS. Consequently, NEXAFS spectroscopy can potentially provide a superior measure of initial state effects [i.e., $q(\mathrm{~A})$ ] relative to XPS. However, $E_{\mathrm{NEXAFS}}$ also depends on UMO energies (defined here as a final state effect). Therefore, NEXAFS spectroscopy is most suitable to probe $q(\mathrm{~A})$ in two situations: (i) when the nature of the core orbital $\rightarrow$ UMO transitions is similar between samples and (ii) when differences in $q(\mathrm{~A})$ are sufficiently large so as to dominate $E_{\text {NEXAFS }}$ differences.

Previous studies have attempted to find the most suitable $q(\mathrm{~A})$ assignment method for ILs. ${ }^{21,56}$ Rigby and Izgorodina assessed the validity of different $q(\mathrm{~A})$ assignment methods using criteria such as basis-set dependence, differences in $q(\mathrm{~A})$ assigned to symmetry-equivalent atoms and invariance of ring atom $q(\mathrm{~A})$ in $\left[\mathrm{C}_{n} \mathrm{C}_{1} \mathrm{Im}\right]^{+}$(1-alkyl-3-methylimidazolium) for increasing $n .{ }^{56}$ ESP-based methods and NBO $q(\mathrm{~A})$ both performed well in these tests. We have previously assessed the validity of AIM, ChelpG, and NBO methods by comparing calculated sulfur charges, $q(\mathrm{~S})$, with the results from XPS and NEXAFS spectroscopy. ${ }^{21}$ Both NBO and ChelpG $q$ (S) correlate well with the experimental data, whereas the AIM $q(\mathrm{~S})$ did not. Furthermore, the ChelpG $q(\mathrm{~S})$ was found to exhibit a high conformational dependence.

A combination of N 1s NEXAFS spectroscopy and XPS has been used to provide an indirect experimental measure of $q(\mathrm{~N})$ for a range of nine ILs (Fig. 1). In our earlier study of $q(\mathrm{~S})$, S was present predominantly in anionic species, whereas in this study, $\mathrm{N}$ features in a more balanced range of cationic and anionic species. $q(\mathrm{~N})$ has been computed for the same ILs using $q(\mathrm{~A})$ assignment methods from each of the three different categories: AIM (an electron density method), NBO (a wavefunction method), and ChelpG (an ESP method). The validity of these $q(\mathrm{~A})$ assignment methods was assessed by comparing calculated $q(\mathrm{~N})$ with spectroscopic results. Finally, based on a combination of experimental and computational results, the relative ordering of $q(\mathrm{~N})$ for the ILs studied has been determined.

\section{METHODS}

\section{A. Experimental methods}

$\left[\mathrm{N}_{8,1,1,0}\right]\left[\mathrm{HSO}_{4}\right]$ (octyl(dimethyl)ammonium hydrogensulfate), $\left[\mathrm{N}_{2,2,1,0}\right][\mathrm{TfO}]$ (diethyl(methyl)ammonium trifluoromethylsulfonate), $\quad\left[\mathrm{C}_{8} \mathrm{C}_{1} \mathrm{Im}\right][\mathrm{SCN}] \quad$ (1-octyl-3methylimidazolium thiocyanate), and $\left[\mathrm{C}_{8} \mathrm{C}_{1} \mathrm{Im}\right]\left[\mathrm{C}(\mathrm{CN})_{3}\right]$ (1-octyl-3-methylimidazolium tricyanomethanide) were purchased from Iolitec; $\left[\mathrm{C}_{4} \mathrm{C}_{1} \mathrm{Im}\right][\mathrm{SCN}]$ (1-butyl-3methylimidazolium thiocyanate) and $\left[\mathrm{C}_{4} \mathrm{C}_{1} \mathrm{Im}\right]\left[\mathrm{N}(\mathrm{CN})_{2}\right]$ (1-butyl-3-methylimidazolium dicyanamide) were purchased from Sigma-Aldrich; and $\left[\mathrm{C}_{6} \mathrm{C}_{1} \mathrm{Im}\right]\left[\mathrm{B}(\mathrm{CN})_{4}\right]$ (1-hexyl-3methylimidazolium tetracyanoborate) was purchased from Merck. $\left[\mathrm{P}_{6,6,6,14}\right]\left[\mathrm{NO}_{3}\right]$ (tetradecyl(trihexyl)phosphonium nitrate), $\left[\mathrm{N}_{4,1,1,0}\right]\left[\mathrm{HSO}_{4}\right]$ (butyl(dimethyl)ammonium hydrogensulfate), $\left[\mathrm{C}_{8} \mathrm{C}_{1} \mathrm{Im}\right] \mathrm{Cl}$ (1-octyl-3-methylimidazolium chloride), and $\left[\mathrm{C}_{8} \mathrm{C}_{1} \mathrm{Im}\right]\left[\mathrm{NTf}_{2}\right]$ (1-octyl-3-methylimidazolium bis[(trifluoromethane)sulfonyl]imide) were synthesised using established literature procedures. ${ }^{57-59}$ The purities of all IL samples synthesised in our laboratories were assessed using ${ }^{1} \mathrm{H}$ NMR and ${ }^{13} \mathrm{C}$ NMR spectroscopy. Sample purity was confirmed through XP survey and core-level spectra (Figs. S2-S9 of the supplementary material for the XP spectra). Furthermore, all measurements were carried out under ultrahigh vacuum (pressure $\sim 10^{-9} \mathrm{mbar}$ ) conditions under which volatile impurities (such as water) are removed.

The dialkylimidazolium ILs were chosen as these all contain nitrogen atoms and are the most important cations for the IL community. A dialkylimidazolium cation was paired with an anion, $\mathrm{Cl}^{-}$, that does not contain nitrogen to allow the dialkylimidazolium cation to be recorded without any anionic nitrogen atom contributions to the $\mathrm{N}$ 1s NEXAFS spectrum. Dialkylimidazolium cations were paired with anions that do contain nitrogen $\left(\left[\mathrm{C}(\mathrm{CN})_{3}\right]^{-},[\mathrm{SCN}]^{-},\left[\mathrm{NTf}_{2}\right]^{-}\right)$so that the anions could be studied and the cations too if possible. $\left[\mathrm{P}_{6,6,6,14}\right]\left[\mathrm{NO}_{3}\right]$ was chosen to allow the $\mathrm{N}$ 1s NEXAFS 
spectrum of the $\left[\mathrm{NO}_{3}\right]^{-}$anion to be recorded without any cationic nitrogen atom contributions to the $\mathrm{N}$ 1s NEXAFS spectrum. The same rationale was used to choose ammoniumbased ILs; ILs were chosen that do contain nitrogen atoms in the anion.

XPS was carried out using a Thermo K-alpha spectrometer utilising $\mathrm{Al} \mathrm{K \alpha}$ radiation $(h v=1486.6 \mathrm{eV})$ and a quartz crystal monochromator set in a $250 \mathrm{~mm}$ Rowland circle. The $\mathrm{X}$-ray spot was focussed at the sample to a size of $400 \mu \mathrm{m}$. The base pressure was $10^{-9} \mathrm{mbar}$, and the analyser was a double focusing $180^{\circ}$ hemisphere with a mean radius $125 \mathrm{~mm}$ that was run in a constant analyser energy mode. The pass energy was set to $200 \mathrm{eV}$ for the survey scan, $20 \mathrm{eV}$ for the core-level spectra, and $50 \mathrm{eV}$ for the VB spectra. The detector was a 128-channel position sensitive detector. The energy scale of the instrument was regularly calibrated using a three-point $(\mathrm{Cu}, \mathrm{Ag}, \mathrm{Au})$ scale. A drop of IL was placed directly onto a stainless steel plate (using a spatula). This plate was placed in a loadlock and the pressure reduced to $10^{-7}$ mbar by pumping down overnight. After attaining the required pressure, the IL was transferred to the analysis chamber $\left(\sim 10^{-9}\right.$ mbar $)$. Etching was carried out using a $500 \mathrm{eV}$ $\mathrm{Ar}^{+}$ion gun. Charge compensation was applied to all ILs studied here and was achieved using a dual beam flood gun which applies both electrons and low energy $\mathrm{Ar}^{+}$ions to the sample.

All XP spectra were fitted using the CASAXPS ${ }^{\mathrm{TM}}$ software. Fitting was carried out using a Shirley background and GL30 line shapes (70\% Gaussian, 30\% Lorentzian). The peak constraints used are outlined in Sec. 1 of the supplementary material. Relative sensitivity factors from Ref. 60 were used to ensure that the experimental stoichiometries matched the nominal stoichiometries. For the majority of ILs, charge referencing was carried out by shifting spectra so that $C_{\text {alkyl }} 1 \mathrm{~s}$ $=285.0 \mathrm{eV}$; this value was obtained from Ref. 34 (see Sec. 1 of the supplementary material for more details on charge referencing).

All NEXAFS spectra were recorded at MAX-lab on beamline I311 on the MAX-II storage ring. ${ }^{61}$ A drop of IL was deposited (with a spatula) onto a molybdenum sample holder (ILs had to be liquid at room temperature for this experimental setup). Samples were pumped slowly to $10^{-6}$ mbar before being transferred to the $\sim 10^{-9}$ mbar analysis chamber. The base pressure in the analysis chamber was in the range of $5 \times 10^{-10}$ mbar. The end-station was equipped with a Scienta SES200 hemispherical electron analyser; spectra were collected using partial electron yield detection. Spectra were fitted with a smoothing spline, using the MATLAB ${ }^{\text {TM }}$ curve fitting toolbox, from which the first-derivative spectrum was generated. $E_{\mathrm{NEXAFS}}$ was then obtained as the energy of the first peak in the first-derivative spectrum (see Fig. S1 of the supplementary material for an example).

\section{B. Computational methods}

Calculations were carried out at the B3LYP/6-311+G(d,p) level using the Gaussian 09 suite of programs. ${ }^{62-66}$ Dispersion was accounted for using Grimme's D3 dispersion correction with Becke-Johnson damping, $\mathrm{D} 3(\mathrm{BJ})$. $\left[\mathrm{P}_{6,6,6,14}\right]\left[\mathrm{NO}_{3}\right]$ is an exception as only D3 was used owing to difficulties with low negative frequencies when using $\mathrm{D} 3(\mathrm{BJ})$ for these structures. ${ }^{67,68}$ The self-consistent field convergence criteria were set to $10^{-7}$ on the energy matrix and $10^{-9}$ on the density matrix. Numerical integration was carried out using a pruned grid with 99 radial shells and 590 angular points per shell.

Optimisations were carried out under no symmetry constraints, and all structures were confirmed as minima by frequency analysis. Initial optimisation was carried out in the gas phase (GP) followed by optimisation in a generalised IL solvent environment using the Solvation Model based on Density (SMD) model, ${ }^{69}$ labeled herein as IL(SMD). The SMD model parameters for $\left[\mathrm{C}_{4} \mathrm{C}_{1} \mathrm{Im}\right]\left[\mathrm{PF}_{6}\right]$ from Ref. 70 have been used. Differences between the solvation environment provided by particular IL solvents are expected to be minimal unless strong H-bonding is present; in this respect, protic ILs may show a greater variation.

Systems were treated as ion pairs, i.e., one cation and one anion. For each ion pair, a range of potentially accessible structures was generated by placing the anion in various positions (based on those isolated for $\left[\mathrm{C}_{4} \mathrm{C}_{1} \mathrm{Im}\right] \mathrm{Cl}$ ) around the lowest energy cation conformer and subsequently optimising the structures in the GP. In particular, for $\left[\mathrm{C}_{4} \mathrm{C}_{1} \mathrm{Im}\right][\mathrm{A}] \mathrm{ILs}$, "in-plane" structures facilitated by H-bonding and "top" and "bottom" structures facilitated by anion-pi interactions were explored. A similar strategy was used for the ammonium- and phosphonium-based [ $\left.\mathrm{E}_{n, m, o, p}\right][\mathrm{A}] \mathrm{ILs}$ (where the central atom $\mathrm{E}$ is nitrogen or phosphorus); anions were placed on each of the unique "tetrahedral faces" or between the ligands and optimised. Subsequently, stable GP structures were optimised within the IL solvent environment IL(SMD). Small rotations of the anion or of the cation alkyl chains within cations are not expected to substantially affect the electrostatic potential or covalent bonding within the ions; thus, an exhaustive search of all minor conformer variants was not carried out. Emphasis was placed on surveying a good range of conformer variants, such as identifying all conformers in which the anion took up substantially different positions around the cation. The number of major conformers identified for each IL differs, ranging from 4 to 11. In many cases, the number of stable conformers is reduced within the IL environment, as is the energy range of the conformers. The energies of the SMD optimised conformers used in this study were all within $26 \mathrm{~kJ} \mathrm{~mol}^{-1}$ of the lowestenergy conformer. Images of the individual GP conformers are presented in Figs. S14-S22 of the supplementary material (the SMD conformers are very similar), and GP and IL(SMD) $\Delta G$, $\Delta E$, and $q(\mathrm{~A})$ are listed in Tables S4-S21 of the supplementary material.

AIM $q(\mathrm{~A})$ were calculated using AIMAll. ${ }^{71} \mathrm{NBO} q(\mathrm{~A})$ were calculated using $\mathrm{NBO}$ version 5.9, overriding the older default version in Gaussian 09. ${ }^{72}$ ChelpG $q(\mathrm{~A})$ were calculated in Gaussian 09 using default settings. The $q(\mathrm{~N})$ reported for $\left[\mathrm{C}_{n} \mathrm{C}_{1} \mathrm{Im}\right][\mathrm{A}] \mathrm{ILs}$ are from calculations using the $\left[\mathrm{C}_{4} \mathrm{C}_{1} \mathrm{Im}\right]^{+}$ cation; the average of both nitrogen atoms is reported in all cases. The $q(\mathrm{~N})$ reported are based on an unweighted average of all the conformers obtained. The accuracy of density functional theory (DFT) methods is $\approx 5 \mathrm{~kJ} \mathrm{~mol}^{-1}$ to $10 \mathrm{~kJ} \mathrm{~mol}^{-1}$; thus, conformers with energies lower than $10 \mathrm{~kJ} \mathrm{~mol}^{-1}$ should be treated as energetically equivalent. Slightly higher energy conformers will be accessible at room temperatures. However, 
on using the IL(SMD) environment, the energy range of all conformers reduced to $<26 \mathrm{~kJ} \mathrm{~mol}^{-1}$. Thus, to remain consistent at both levels of calculation [i.e., $q(\mathrm{~N})$ of GP and IL(SMD) computed using the same structures], the higher energy GP structures were included in the averages. In MD simulations, an average point charge model is required, as only a single charge distribution is applied to all molecules; thus, the use of an average over all low-energy conformers is advantageous. $q(\mathrm{~N})$ for all individual conformers both in the GP and IL(SMD) are reported in Tables S4-S21 of the supplementary material and can be individually interrogated.

\section{RESULTS AND DISCUSSION}

\section{A. Experimental results}

Figure 2 shows the N 1s XP spectra and N 1s NEXAFS spectra for the ILs studied. Each separate nitrogen electronic environment gives a single peak in the XP spectra [Fig. 2(a)]. For example, the $\left[\mathrm{C}_{4} \mathrm{C}_{1} \mathrm{Im}\right][\mathrm{SCN}] \mathrm{N}$ 1s XP spectrum contains two peaks in an intensity ratio of $2: 1$; the more intense peak is from the two nitrogen atoms in $\left[\mathrm{C}_{4} \mathrm{C}_{1} \mathrm{Im}\right]^{+}$(which are indistinguishable by XPS ${ }^{42}$ ), and the other peak ${ }^{73}$ is from the single nitrogen atom in $[\mathrm{SCN}]^{-}$. Peaks in the NEXAFS spectra are identified using a combination of experiments (identifying peaks by a process of elimination) and time-dependent DFT calculations; see Ref. 74 for more details on peak identification in NEXAFS spectra.

The shape of the N 1s NEXAFS spectra [Fig. 2(b)] varied significantly between the different nitrogen environments. A single, sharp peak is observed for the majority of nitrogen environments probed (e.g., for $\left[\mathrm{C}_{8} \mathrm{C}_{1} \mathrm{Im}\right]^{+},[\mathrm{SCN}]^{-}$, and $\left[\mathrm{NO}_{3}\right]^{-}$), but a broad feature (with no clear peak) was observed for $\left[\mathrm{N}_{4,1,1,0}\right]^{+}$and $\left[\mathrm{N}_{2,2,1,0}\right]^{+}$(see Ref. 74 for more details on the shape of these features). No clear peak is observed for $\left[\mathrm{NTf}_{2}\right]^{-}$; this observation is consistent with previous studies that suggest $\mathrm{N}$ 1s peaks for $\left[\mathrm{NTf}_{2}\right]^{-}$and $\left[\mathrm{C}_{4} \mathrm{C}_{1} \mathrm{Im}\right]^{+}$occur at similar photon energies. ${ }^{74-77} E_{\text {NEXAFS values can vary owing to the identity }}$ of the UMOs that the electron from the core $\mathrm{N}$ 1s orbital is excited into, i.e., by $\mathrm{N} 1 \mathrm{~s} \rightarrow \mathrm{UMO}$; this is a final state effect. Thus, interpreting $E_{\mathrm{NEXAFS}}$ in terms of $q(\mathrm{~N})$ (i.e., an initial state effect) requires similar N 1s $\rightarrow$ UMO transitions, which is not the case for the wide range of nitrogen covalent bonding environments studied here. Evidence of the differences in $\mathrm{N} 1 \mathrm{~s} \rightarrow \mathrm{UMO}$ can be found in the strongly varying edge shapes of the $\mathrm{N}$ 1s NEXAFS spectra for the ILs studied here [e.g., compare $\mathrm{N}$ 1s spectra for $\left[\mathrm{N}_{4,1,1,0}\right]\left[\mathrm{HSO}_{4}\right]$ and $\left[\mathrm{C}_{8} \mathrm{C}_{1} \mathrm{Im}\right] \mathrm{Cl}$ in Fig. 2(b)]. The differences in edge shape suggest that the nature of probed excited states differ significantly between the ammonium-based and imidazolium-based ILs. However, for all four of the $\left[\mathrm{C}_{n} \mathrm{C}_{1} \mathrm{Im}\right][\mathrm{A}]$ ILs studied here, the nitrogen atoms in the $\left[\mathrm{C}_{n} \mathrm{C}_{1} \mathrm{Im}\right]^{+}$cation gave a single Gaussian-shaped peak [Fig. 2(b)], as did time-dependent DFT calculations (see Ref. 74). These results strongly suggest that the UMOs of interest are the same for all four $\left[\mathrm{C}_{n} \mathrm{C}_{1} \mathrm{Im}\right][\mathrm{A}] \mathrm{ILs}$. Consequently, the final state effect contribution from the UMOs to $E_{\text {NEXAFS }}$ are expected to be the same for all four $\left[\mathrm{C}_{n} \mathrm{C}_{1} \mathrm{Im}\right][\mathrm{A}] \mathrm{ILs}$. For a more detailed analysis of these NEXAFS spectra, see Ref. 74.

$\mathrm{N} 1 \mathrm{~s} E_{\mathrm{B}}$ and $E_{\mathrm{NEXXFS}}$ values are shown in Table I. A more positive $q(\mathrm{~A})$ is expected to lead to a larger value of either $E_{\mathrm{B}}$ or $E_{\mathrm{NEXAFS}}$. Both $E_{\mathrm{B}}$ and $E_{\mathrm{NEXAFS}}$ results suggest that $q(\mathrm{~N})$ increases (becomes more positive) in the order $\left[\mathrm{X}(\mathrm{CN})_{y}\right]^{-}$ $<\left[\mathrm{C}_{n} \mathrm{C}_{1} \mathrm{Im}\right]^{+}<\left[\mathrm{NO}_{3}\right]^{-}$, but unfortunately trends in $E_{\mathrm{B}}$ and $E_{\text {NEXAFS }}$ are inconsistent for the other ILs (potential reasons for this will be discussed below in Sec. III C).

The $\mathrm{N} 1 \mathrm{~s} E_{\mathrm{B}}$ is larger for $\left[\mathrm{C}_{n} \mathrm{C}_{1} \mathrm{Im}\right]^{+}$than $\left[\mathrm{X}(\mathrm{CN})_{y}\right]^{-}$ (Table I), indicating that $\left[\mathrm{C}_{n} \mathrm{C}_{1} \mathrm{Im}\right]^{+}$has a more stable $\mathrm{N}$ 1s core orbital than $\left[\mathrm{X}(\mathrm{CN})_{y}\right]^{-}$. The implication is that the more stable orbital experiences a more positive (or less negative) charge. The sign of $q(\mathrm{~N})$ cannot be unambiguously
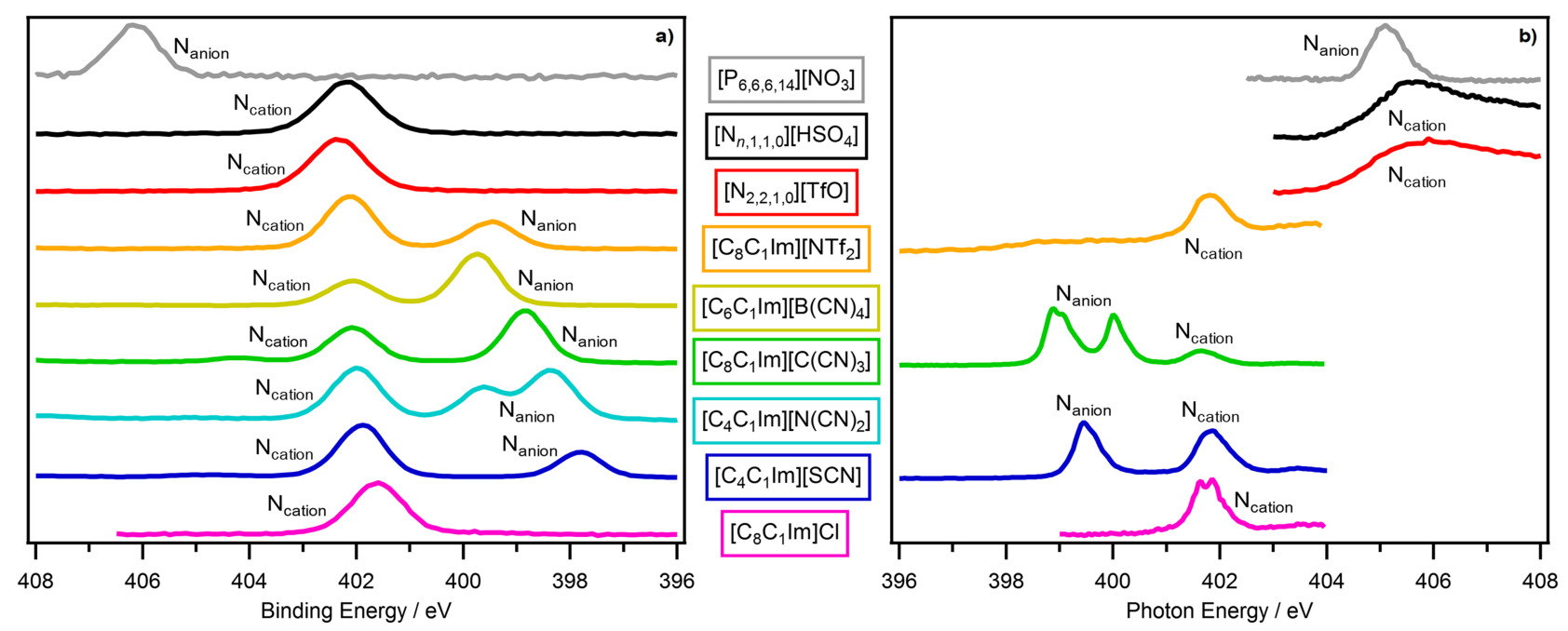

FIG. 2. (a) XPS N 1s core-level spectra and (b) NEXAFS N 1s spectra for all ILs studied. The imidazolium peak occurs between $E_{\mathrm{B}}=401.6$ eV and $E_{\mathrm{B}}$ $=402.1 \mathrm{eV}$ for the XPS data and at $h v=401.9 \mathrm{eV}$ for the NEXAFS spectroscopy data. All XP spectra have been charge referenced, as described in Sec. 1 of the supplementary material. The features at $h v<400 \mathrm{eV}$ for $\left[\mathrm{C}_{8} \mathrm{C}_{1} \mathrm{Im}\right]\left[\mathrm{NTf}_{2}\right]$ are most likely owing to sample damage (see Ref. 74 for more details on peak identification in NEXAFS spectra). NEXAFS spectra have not been recorded for $\left[\mathrm{C}_{6} \mathrm{C}_{1} \mathrm{Im}\right]\left[\mathrm{B}(\mathrm{CN})_{4}\right]$ or $\left[\mathrm{C}_{4} \mathrm{C}_{1} \mathrm{Im}\right]\left[\mathrm{N}(\mathrm{CN})_{2}\right]$. For $\left[\mathrm{N}_{n, 1,1,0}\right]\left[\mathrm{HSO} \mathrm{O}_{4}\right]$, the XP spectrum is for $n=8$ and the NEXAFS spectrum is for $n=4$. By convention, the binding energy and photon energy $x$-axes are plotted in opposite directions. 
TABLE I. Calculated $q(\mathrm{~N})$ from ion pair (GP) calculations for the three different $q(\mathrm{~N})$ assignment methods, $\mathrm{N} 1 \mathrm{~s}$ binding energies $\left(E_{\mathrm{B}}\right)$, and $\mathrm{N} 1 \mathrm{~s}$ NEXAFS edge energies $\left(E_{\mathrm{NEXAFS}}\right)$ for a range of ILs.

\begin{tabular}{lcccccc}
\hline \hline Ionic liquid & & $\begin{array}{c}q(\mathrm{~N}) \text { from } \\
\text { AIM }(e)\end{array}$ & $\begin{array}{c}q(\mathrm{~N}) \text { from } \\
\text { ChelpG }(e)\end{array}$ & $\begin{array}{c}q(\mathrm{~N}) \text { from } \\
\text { NBO }(e)\end{array}$ & $\begin{array}{c}E_{\mathrm{B}}( \pm 0.1) \\
(\mathrm{eV})\end{array}$ & $\begin{array}{c}E_{\mathrm{NEXAFS}}( \pm 0.1) \\
(\mathrm{eV})\end{array}$ \\
\hline$\left[\mathrm{C}_{8} \mathrm{C}_{1} \mathrm{Im}\right]\left[\mathrm{NTf}_{2}\right]$ & Anion & -1.6 & -0.7 & -1.2 & 399.5 & $\mathrm{NP}^{\mathrm{a}}$ \\
{$\left[\mathrm{C}_{4} \mathrm{C}_{1} \mathrm{Im}\right][\mathrm{SCN}]$} & Anion & -1.3 & -0.7 & -0.6 & $397.8^{\mathrm{b}}$ & 399.3 \\
{$\left[\mathrm{C}_{4} \mathrm{C}_{1} \mathrm{Im}\right]\left[\mathrm{N}^{\mathrm{c}}(\mathrm{CN})_{2}\right]$} & Anion & -1.2 & -0.7 & -0.7 & 399.7 & $\mathrm{X}^{\mathrm{d}}$ \\
{$\left[\mathrm{C}_{4} \mathrm{C}_{1} \mathrm{Im}\right]\left[\mathrm{N}(\mathrm{CN})_{2}\right]$} & Anion & -1.2 & -0.7 & -0.6 & 398.4 & $\mathrm{X}^{\mathrm{d}}$ \\
{$\left[\mathrm{C}_{8} \mathrm{C}_{1} \mathrm{Im}\right]\left[\mathrm{C}(\mathrm{CN})_{3}\right]$} & Anion & -1.2 & -0.6 & -0.4 & 398.8 & 398.8 \\
{$\left[\mathrm{C}_{6} \mathrm{C}_{1} \mathrm{Im}\right]\left[\mathrm{B}(\mathrm{CN})_{4}\right]$} & Anion & -1.2 & -0.5 & -0.4 & 399.8 & $\mathrm{X}^{\mathrm{d}}$ \\
{$\left[\mathrm{P}_{6,6,6,14}\right]\left[\mathrm{NO}_{3}\right]$} & Anion & +0.8 & +1.0 & +0.7 & 406.1 & 404.8 \\
{$\left[\mathrm{C}_{8} \mathrm{C}_{1} \mathrm{Im}\right] \mathrm{Cl}$} & Cation & -1.2 & +0.1 & -0.4 & 401.6 & 401.5 \\
{$\left[\mathrm{C}_{4} \mathrm{C}_{1} \mathrm{Im}\right][\mathrm{SCN}]$} & Cation & -1.2 & +0.1 & -0.4 & $401.9^{\mathrm{b}}$ & 401.5 \\
{$\left[\mathrm{C}_{4} \mathrm{C}_{1} \mathrm{Im}\right]\left[\mathrm{N}(\mathrm{CN})_{2}\right]$} & Cation & -1.2 & +0.1 & -0.4 & 402.0 & $\mathrm{X}^{\mathrm{d}}$ \\
{$\left[\mathrm{C}_{8} \mathrm{C}_{1} \mathrm{Im}\right]\left[\mathrm{C}(\mathrm{CN})_{3}\right]$} & Cation & -1.2 & +0.2 & -0.4 & 402.1 & 401.4 \\
{$\left[\mathrm{C}_{6} \mathrm{C}_{1} \mathrm{Im}\right]\left[\mathrm{B}(\mathrm{CN})_{4}\right]$} & Cation & -1.2 & +0.1 & -0.4 & 402.1 & $\mathrm{X}^{\mathrm{d}}$ \\
{$\left[\mathrm{C}_{8} \mathrm{C}_{1} \mathrm{Im}\right]\left[\mathrm{NTf}{ }_{2}\right]$} & Cation & -1.2 & +0.1 & -0.4 & 402.1 & 401.5 \\
{$\left[\mathrm{~N}_{2,2,1,0}\right][\mathrm{TfO}]$} & Cation & -0.9 & +0.1 & -0.5 & 402.4 & 404.8 \\
{$\left[\mathrm{~N}_{4,1,1,0}\right]\left[\mathrm{HSO} \mathrm{H}_{4}\right]$} & Cation & -1.0 & +0.2 & -0.5 & $402.2^{\mathrm{e}}$ & 404.9 \\
\hline \hline
\end{tabular}

${ }^{a} \mathrm{NP}$ indicates that no clear peak was observed in the $\mathrm{N} 1 \mathrm{~s}$ NEXAFS spectrum for this ion.

${ }^{\mathrm{b}}\left[\mathrm{C}_{8} \mathrm{C}_{1} \mathrm{Im}\right][\mathrm{SCN}]$ was used to obtain this $E_{\mathrm{B}}$ value.

${ }^{\mathrm{c}}$ This is used to differentiate the electronically non-equivalent anionic nitrogen atoms in $\left[\mathrm{N}(\mathrm{CN})_{2}\right]^{-}$.

${ }^{\mathrm{d}} \mathrm{X}$ indicates that the data have not been recorded.

${ }^{\mathrm{e}}\left[\mathrm{N}_{8,1,1,0}\right]\left[\mathrm{HSO}_{4}\right]$ was used to obtain this $E_{\mathrm{B}}$ value.

determined; only the relative difference between the environments can be established. Crucially, the smallest experimental $E_{\mathrm{B}}$ difference between $\left[\mathrm{C}_{n} \mathrm{C}_{1} \mathrm{Im}\right]^{+}$and the cyano nitrogen atoms in $\left[\mathrm{X}(\mathrm{CN})_{y}\right]^{-}$is $1.9 \mathrm{eV}$. We have previously suggested that owing to final state effects, differences in $E_{\mathrm{B}}<0.5 \mathrm{eV}$ should not be interpreted in terms of $q(\mathrm{~A}) .{ }^{21}$ Therefore, the difference of $1.9 \mathrm{eV}$ is large enough to be assigned to differences in initial state effects, i.e., differences in $q(\mathrm{~N})$.

There are excellent matches between literature data and both our NEXAFS spectroscopy and XPS data. Our $\mathrm{N}$ 1s XP spectra have approximately the same shape as those published in the literature, where available, e.g., $\left[\mathrm{C}_{n} \mathrm{C}_{1} \operatorname{Im}\right]\left[\mathrm{N}(\mathrm{CN})_{2}\right],{ }^{34,78,79}\left[\mathrm{C}_{n} \mathrm{C}_{1} \operatorname{Im}\right]\left[\mathrm{NTf}_{2}\right],{ }^{34,41,80}$ and $\left[\mathrm{C}_{n} \mathrm{C}_{1} \mathrm{Im}\right][\mathrm{SCN}] .{ }^{73}$ When the $E_{\mathrm{B}}$ scales for the literature data are charge referenced using the same method as here, the $\mathrm{N} 1 \mathrm{~s}$ $E_{\mathrm{B}}$ values for both cationic and anionic atoms match our data, within experimental error, e.g., $E_{\mathrm{B}}=402.1 \pm 0.1 \mathrm{eV}$ for $\mathrm{N}_{\text {cation }}$ $1 \mathrm{~s}$ for $\left[\mathrm{C}_{n} \mathrm{C}_{1} \mathrm{Im}\right]\left[\mathrm{NTf}_{2}\right]^{34,41}$ and $E_{\mathrm{B}}=399.5 \mathrm{eV}$ for $\mathrm{N}_{\text {anion }} 1 \mathrm{~s}$ for $\left[\mathrm{C}_{n} \mathrm{C}_{1} \mathrm{Im}\right]\left[\mathrm{NTf}_{2}\right] .^{34,41}$ The only exception is the $\mathrm{N} 1 \mathrm{~s} E_{\mathrm{B}}$ value for $\left[\mathrm{P}_{6,6,6,14}\right]\left[\mathrm{NO}_{3}\right]$, which differs from the $\mathrm{N} 1 \mathrm{~s} E_{\mathrm{B}}$ value for $\left[\mathrm{C}_{8} \mathrm{C}_{1} \mathrm{Im}\right]\left[\mathrm{NO}_{3}\right]$ by $0.3 \mathrm{eV}$; ${ }^{41}$ such differences in $E_{\mathrm{B}}$ values for anionic atoms due to the identity of the cation have been rationalised in terms of differences in anion-to-cation charge transfer. ${ }^{81}$ Our N 1s NEXAFS spectra have approximately the same shape as those published in the literature, where available, e.g., $\left[\mathrm{C}_{n} \mathrm{C}_{1} \operatorname{Im}\right]\left[\mathrm{NTf}_{2}\right]^{75-77}$ (further detail on the comparison of NEXAFS spectra can be found in Ref. 74).

\section{B. Computational results}

Calculated GP $q(\mathrm{~N})$ (averaged values) are provided in Table I and plotted in Fig. $3[q(\mathrm{~N})$ for IL(SMD) are similar; Table S4 and Fig. S12 of the supplementary material]. For the $\left[\mathrm{X}(\mathrm{CN})_{y}\right]^{-}$anions, similar trends are found for all three $q(\mathrm{~N})$ assignment methods (AIM, NBO, and ChelpG). For the cyano nitrogen atoms: $q(\mathrm{~N})$ is consistently slightly more negative for $[\mathrm{SCN}]^{-}$and $\left[\mathrm{N}(\mathrm{CN})_{2}\right]^{-}$compared with $\left[\mathrm{C}(\mathrm{CN})_{3}\right]^{-}$ and $\left[\mathrm{B}(\mathrm{CN})_{4}\right]^{-}$[both in the GP and $\left.\mathrm{IL}(\mathrm{SMD})\right]$. A smaller $q(\mathrm{~N})$ for the larger anions (with more cyano groups) can be rationalised as the overall anion charge being spread over more cyano groups in $\left[\mathrm{X}(\mathrm{CN})_{y}\right]^{-}$as $y$ increases from $y=1$ to $y=4$.

The $q(\mathrm{~N})$ for nitrogen atoms in the cations show the greatest differences between the three $q(\mathrm{~N})$ assignment methods (Fig. 3). For example, for the cation in $\left[\mathrm{C}_{4} \mathrm{C}_{1} \mathrm{Im}\right][\mathrm{A}]$, the range of $q(\mathrm{~N})$ values is $\sim 1.3 \mathrm{eV}$ (from AIM to ChelpG), whereas for the anion in $\left[\mathrm{C}_{4} \mathrm{C}_{1} \mathrm{Im}\right][\mathrm{SCN}]$, the range of $q(\mathrm{~N})$ values is $0.7 \mathrm{eV}$ (from AIM to NBO, Table I). For all three cations studied computationally (i.e., $\left[\mathrm{C}_{4} \mathrm{C}_{1} \mathrm{Im}\right]^{+},\left[\mathrm{N}_{2,2,1,0}\right]^{+}$, and $\left[\mathrm{N}_{4,1,1,0}\right]^{+}$), $q(\mathrm{~N})$ are slightly positive for ChelpG, but $q(\mathrm{~N})$ are negative for both AIM and NBO (Fig. 3).

The $q(\mathrm{~N})$ for nitrogen atoms in the cations are essentially constant for different $\left[\mathrm{C}_{4} \mathrm{C}_{1} \mathrm{Im}\right][\mathrm{A}] \mathrm{ILs}$, i.e., independent of the anion, A (Table I). This observation holds for all three $q(\mathrm{~N})$ assignment methods. For AIM, $q(\mathrm{~N})=-1.2 e$; for NBO, $q(\mathrm{~N})$ $=-0.4 e ;$ and for ChelpG, $q(\mathrm{~N})=+0.1 e$.

For both AIM and NBO, the values of $q(\mathrm{~N})$ are the same for both the cation and the anion in the $\left[\mathrm{C}_{4} \mathrm{C}_{1} \operatorname{Im}\right]\left[\mathrm{X}(\mathrm{CN})_{y}\right]$ ILs $\left[q(\mathrm{~N})_{\mathrm{AIM}} \sim-1.2 \pm 0.1 e\right.$ and $\left.q(\mathrm{~N})_{\mathrm{NBO}} \sim-0.5 \pm 0.2 e\right]$. For ChelpG, the values of $q(\mathrm{~N})$ for the cation and anion in the $\left[\mathrm{C}_{4} \mathrm{C}_{1} \mathrm{Im}\right]\left[\mathrm{X}(\mathrm{CN})_{y}\right]$ ILs are very different: $q(\mathrm{~N})_{\mathrm{ChelpG}}$ $\sim-0.6 \pm 0.1 e$ for the anion and $q(\mathrm{~N})_{\mathrm{ChelpG}} \sim+0.1 \pm 0.1 e$ for the cation.

For all of the ILs studied (apart from $\left[\mathrm{C}_{4} \mathrm{C}_{1} \mathrm{Im}\right]\left[\mathrm{NO}_{3}\right]$ ), there is a clear difference in the magnitude of $q(\mathrm{~N})$ for the three different charge assignment methods used here. Of these 


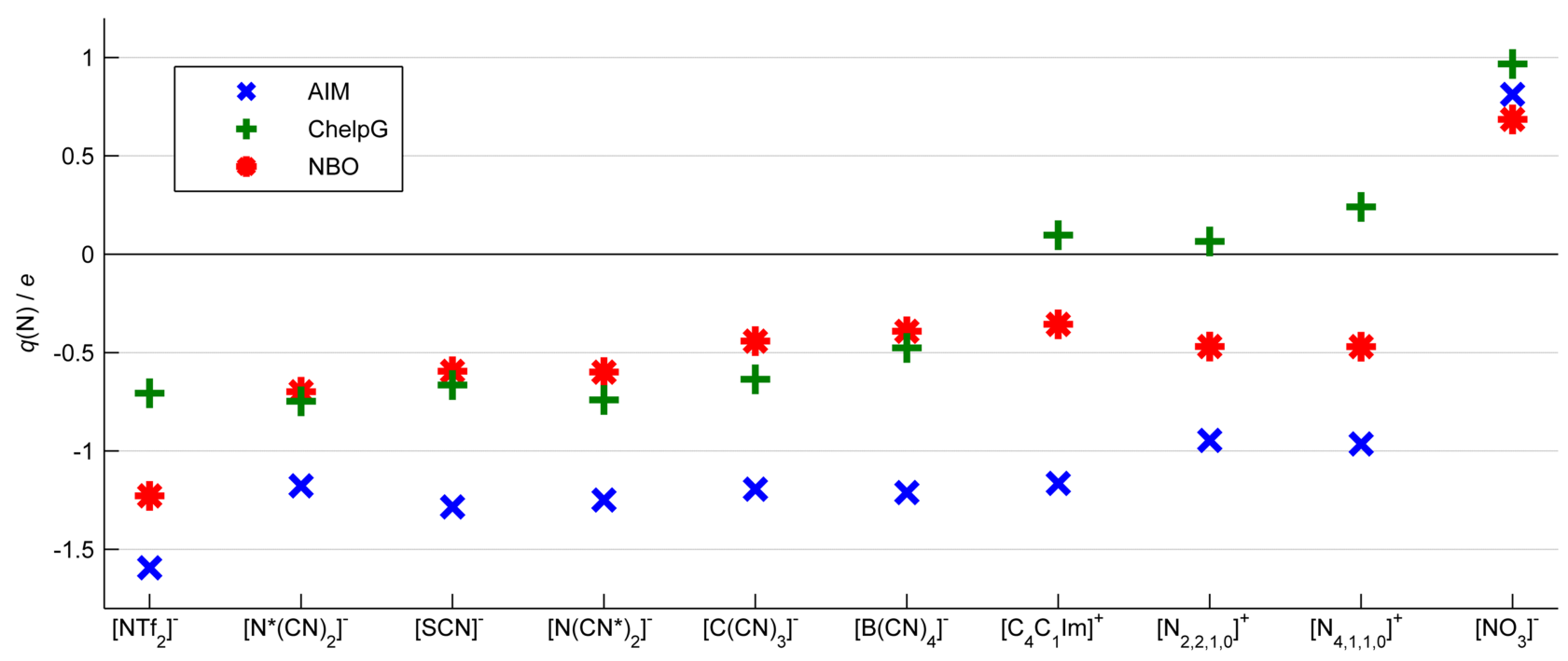

FIG. 3. Average $q(\mathrm{~N})$ values for all ions studied from ion pair (GP) calculations. ${ }^{*}$ is used to distinguish between the electronically non-equivalent nitrogen atoms in $\left[\mathrm{N}(\mathrm{CN})_{2}\right]^{-}$. For all anions, the counterion is $\left[\mathrm{C}_{4} \mathrm{C}_{1} \mathrm{Im}\right]^{+}$; the $\left[\mathrm{C}_{4} \mathrm{C}_{1} \mathrm{Im}\right]^{+}$data point represents an average of all $\left[\mathrm{C}_{4} \mathrm{C}_{1} \mathrm{Im}\right][\mathrm{A}] \mathrm{ILs}$ studied.

methods, AIM gives the largest magnitude $q(\mathrm{~N})$ (i.e., highest charge polarisation). Such a difference is significant and could lead to very different intermolecular interactions for ILs if AIM $q(\mathrm{~N})$ were used for parameterising force fields for MD simulations.

The range of $q(\mathrm{~N})$ over the different conformers is shown for all systems in Fig. 4. AIM and NBO $q(\mathrm{~N})$ differ by $<0.1 e$ over all conformers, whereas ChelpG $q(\mathrm{~N})$, as anticipated, exhibits a much larger conformational dependence of up to $0.3 e$ in some cases. Therefore, conformational effects are negligible for AIM and NBO $q(\mathrm{~N})$ but can be significant for ChelpG $q(\mathrm{~N})$.

The computed ChelpG $q(\mathrm{~N})$ that show the largest range for the anion are $\left[\mathrm{C}_{4} \mathrm{C}_{1} \mathrm{Im}\right]\left[\mathrm{NTf}_{2}\right]$ and $\left[\mathrm{P}_{6,6,6,14}\right]\left[\mathrm{NO}_{3}\right]$ and for the cation are $\left[\mathrm{N}_{2,2,1,0}\right][\mathrm{TfO}]$ and $\left[\mathrm{N}_{4,1,1,0}\right]\left[\mathrm{HSO}_{4}\right]$. The standard deviation for the averages (of all conformers) are $0.10 e, 0.08 e$, $0.13 e$, and $0.12 e$ (for $\left[\mathrm{C}_{4} \mathrm{C}_{1} \operatorname{Im}\right]\left[\mathrm{NTf}_{2}\right],\left[\mathrm{P}_{6,6,6,14}\right]\left[\mathrm{NO}_{3}\right]$,
$\left[\mathrm{N}_{2,2,1,0}\right][\mathrm{TfO}]$, and $\left[\mathrm{N}_{4,1,1,0}\right]\left[\mathrm{HSO}_{4}\right]$, respectively). These values are all in the region of $0.1 e$.

The computed ChelpG $q(\mathrm{~N})$ that show the largest range for the cation is found in $\left[\mathrm{N}_{2,2,1,0}\right][\mathrm{TfO}]$ and $\left[\mathrm{N}_{4,1,1,0}\right]\left[\mathrm{HSO}_{4}\right]$. Examining these structures, there are clear differences in the cation-anion association, which lead to a change in charge polarisation and ESP (Fig. 5). For example, in $\left[\mathrm{N}_{2,2,1,0}\right]$ [TfO], the higher-energy conformer $[q(\mathrm{~N})=-0.1 e]$ has a "free" protic $\mathrm{N}-\mathrm{H}$, with the nitrogen exposed on the exterior of the ion pair. By contrast, in the lowest-energy conformer $[q(\mathrm{~N})=+0.2 e]$, the protic $\mathrm{N}-\mathrm{H}$ forms a $\mathrm{H}$-bond with the oxygen atoms of the $[\mathrm{TfO}]^{-}$anion; in this case, the nitrogen atom is buried within the ion pair.

We tested the sensitivity of $q(\mathrm{~N})$ to the addition of a solvent continuum model IL(SMD) (see Tables S4-S21 of the supplementary material). The difference in $q(\mathrm{~N})$ between GP and $\mathrm{IL}(\mathrm{SMD})$ is $<0.1 e$ in most cases, and the values had a
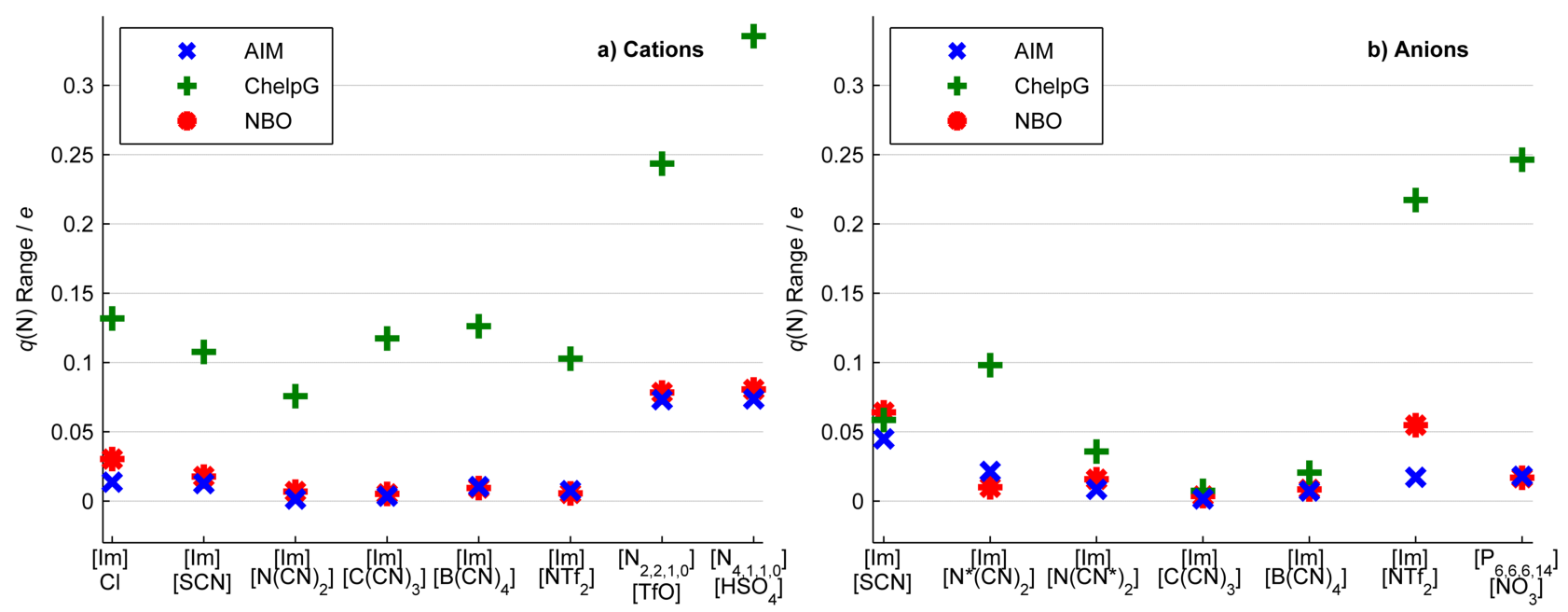

FIG. 4. Range of calculated $q(\mathrm{~N})$ between different conformers [the difference between the maximum and minimum $q(\mathrm{~N})$ values for each IL] for (a) nitrogen atoms in the cations and (b) nitrogen atoms in the anions. All calculations were carried out on ion pair (GP) conformers. [Im] $]^{+}$is used as shorthand for $\left[\mathrm{C}_{4} \mathrm{C}_{1} \mathrm{Im}\right]^{+}$. 

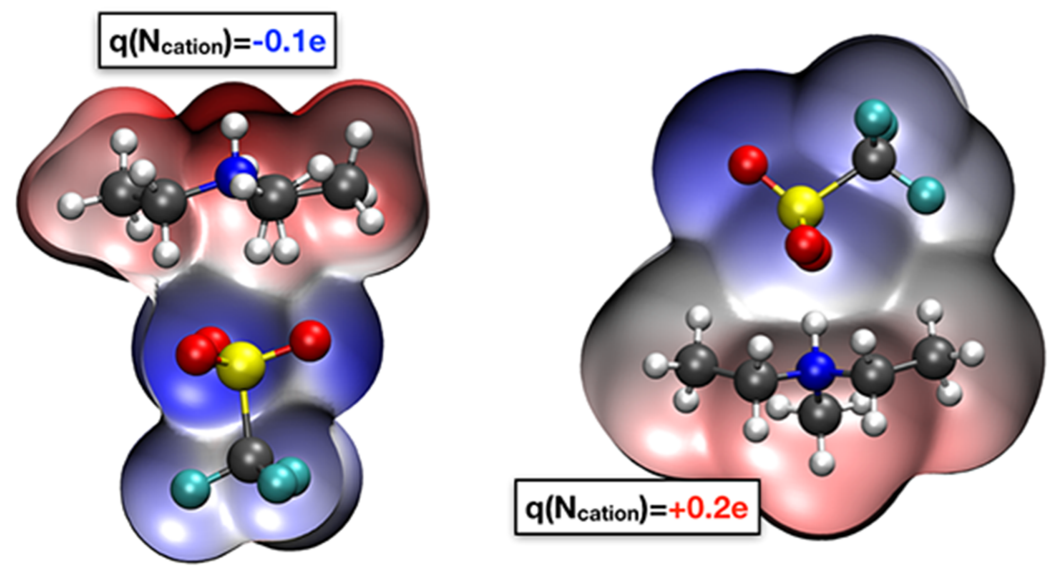

FIG. 5. Two conformers of $\left[\mathrm{N}_{2,2,1,0}\right][\mathrm{TfO}]$ that show the largest variation in $q(\mathrm{~N})$ for ChelpG; the density isosurface is computed at $0.004 \mathrm{au}$, and the ESP ranges from $+0.1 e$ (red) through to $-0.1 e$ (blue).

maximum difference of $<0.2 e$. The lack of change in $q(\mathrm{~N})$ on moving from the GP to an IL(SMD) solvent environment suggests that the electronic structure and ESP are not changing significantly. These results suggest that computational models that account for a greater degree of intermolecular interaction (i.e., clusters of ions) will not significantly change the calculated $q(\mathrm{~N})$, consistent with our earlier study. ${ }^{21}$

\section{Computational-experimental correlations}

Calculated $q(\mathrm{~N})$ data are plotted against the $\mathrm{N} 1 \mathrm{~s} E_{\mathrm{B}}$ from XPS [Fig. 6(a)] and the $\mathrm{N}$ 1s $E_{\text {NEXAFS from NEXAFS }}$ spectroscopy [Fig. 6(b)]. In both Figs. 6(a) and 6(b), a single data point is used for the $\left[\mathrm{C}_{4} \mathrm{C}_{1} \mathrm{Im}\right]^{+}$cation. The experimental data points were generated by averaging $E_{\mathrm{B}}$

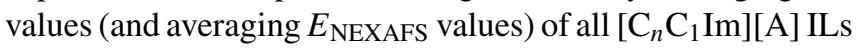
studied.

Poor correlations are found between the calculated $q(\mathrm{~N})$ and $E_{\mathrm{NEXAFS}}\left(R^{2}=0.19,0.30\right.$, and 0.71 for $\mathrm{NBO}$,
AIM, and ChelpG, respectively). A comparison of $E_{\mathrm{NEXAFS}}$ and $q(\mathrm{~N})$ values for $\left[\mathrm{NO}_{3}\right]^{-}$and alkylammonium cations highlights how poorly NEXAFS spectroscopy performs for our dataset. All three $q(\mathrm{~N})$ assignment methods used here give very different $q(\mathrm{~N})$ values for $\left[\mathrm{NO}_{3}\right]^{-}$versus the two alkylammonium cations (see Table I), for example, $q(\mathrm{~N})_{\mathrm{ChelpG}}$ $=+1.0 e$ for $\left[\mathrm{C}_{4} \mathrm{C}_{1} \mathrm{Im}\right]\left[\mathrm{NO}_{3}\right]$, whereas $q(\mathrm{~N})_{\mathrm{ChelpG}}=+0.2 e$ for $\left[\mathrm{N}_{4,1,1,0}\right]\left[\mathrm{HSO}_{4}\right]$. However, $E_{\mathrm{NEXAFS}}$ for $\left[\mathrm{NO}_{3}\right]^{-}$and the two alkylammonium cations are the same (within experimental error). This poor performance is likely due to the very different UMOs (i.e., very different final state effects) for $\left[\mathrm{NO}_{3}\right]^{-}$and the two alkylammonium cations, which have a strong influence on the $E_{\text {NEXAFS }}$ values. These poor correlations are anticipated based on our findings for sulfur atoms in $\mathrm{ILs}^{21}$ and the very different UMOs (i.e., very different final state effects) that occur for our structurally diverse nitrogen dataset (for which we presented experimental evidence in Sec. III A). Therefore, the poor correlations are due to $E_{\mathrm{NEXAFS}}$ values giving a poor measure of $q(\mathrm{~N})$ (i.e., initial state effects)
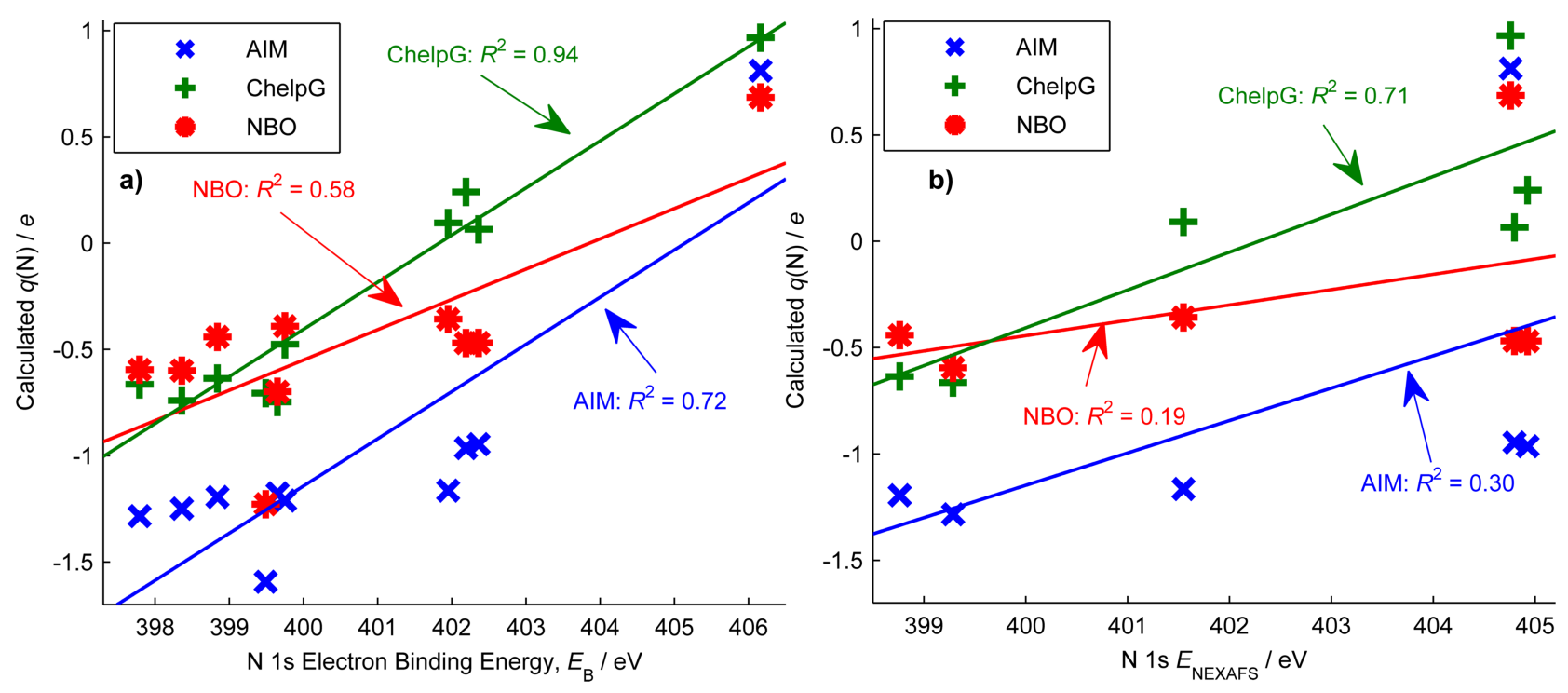

FIG. 6. Calculated $q(\mathrm{~N})$ data plotted against (a) $\mathrm{N} 1 \mathrm{~s} E_{\mathrm{B}}$ from XPS and (b) $\mathrm{N} 1 \mathrm{~s} E_{\mathrm{NEXAFS}}$ from NEXAFS spectroscopy. In both cases, a single data point is used for the imidazolium cation, which was generated by averaging values of all ILs studied (this value was $E_{\mathrm{B}}=401.9 \mathrm{eV}$ and $E_{\mathrm{NEXAFS}}=401.5 \mathrm{eV}$ ). The slopes of linear regression lines (i.e., $m$ in $y=m x+c$ ) are (a) $m=0.22$ (AIM), $m=0.22$ (ChelpG), and $m=0.14$ (NBO) and (b) $m=0.30$ (AIM), $m=0.18$ (ChelpG), and $m=0.07(\mathrm{NBO})$. 
for our dataset of nine ILs. Consequently, we will not use $E_{\text {NEXAFS }}$ values to draw conclusions on the quality of the different $q(\mathrm{~N})$ assignment methods for this IL dataset. However, NEXAFS spectroscopy can provide excellent insight into $q(\mathrm{~A})$ when the IL dataset studied contains only structurally very similar ions, e.g., when $q(\mathrm{~N})$ is probed for dialkylimidazoliumcontaining ILs ( $E_{\mathrm{NEXAFS}}$ values for $\left[\mathrm{C}_{n} \mathrm{C}_{1} \mathrm{Im}\right][\mathrm{A}] \mathrm{ILs}$, along with $E_{\text {NEXAFS }}$ for other ILs, will be considered in another publication).

Significantly better correlations are found between $q(\mathrm{~N})$ and $E_{\mathrm{B}}\left(R^{2}=0.58,0.72\right.$, and 0.94 for NBO, AIM, and ChelpG, respectively) than between $q(\mathrm{~N})$ and $E_{\mathrm{NEXAFS}}$. We believe this finding is because $E_{\mathrm{B}}$ values are not influenced by the identity of the UMOs (unlike $E_{\text {NEXAFS }}$ values). It is expected that the contribution of electron relaxation to the overall final state effects will be larger for $E_{\mathrm{B}}$ than for $E_{\mathrm{NEXAFS}}$. However, for this particular dataset, the final state effects are dominated by the identity of the UMOs. Overall, we believe that $E_{\mathrm{B}}$ values (rather than $E_{\mathrm{NEXAFS}}$ values) provide a superior measure of $q(\mathrm{~N})$ for this set of ILs.

The correlation between $E_{\mathrm{B}}$ and calculated (average) $q(\mathrm{~N})$ is best for the ChelpG values. This finding is in contrast to our earlier finding that $\mathrm{NBO}$ was the best method for calculating $q(\mathrm{~S}) .{ }^{21}$ One possible reason why ChelpG $q(\mathrm{~N})$ correlate better with nitrogen $E_{\mathrm{B}}$ than sulfur $E_{\mathrm{B}}$ values is the relatively exposed nature of the nitrogen atoms in our current study, as opposed to the buried nature of sulfur atoms previously examined. The major drawback of using ChelpG $q(\mathrm{~N})$ is the non-physical conformational dependence observed for a small number of ILs.

A key difference between the computational methods (AIM, NBO, and ChelpG) is the relative $q(\mathrm{~N})$ assigned to the nitrogen in the $\left[\mathrm{C}_{4} \mathrm{C}_{1} \mathrm{Im}\right]^{+}$cations versus the cyano nitrogen atoms in the $\left[\mathrm{X}(\mathrm{CN})_{y}\right]^{-}$anions. In Sec. III A, we concluded from the XPS experiments that $q(\mathrm{~N})$ for $\left[\mathrm{C}_{n} \mathrm{C}_{1} \mathrm{Im}\right]^{+}$is significantly more positive than for the cyano nitrogen atoms in $\left[\mathrm{X}(\mathrm{CN})_{y}\right]^{-}$. AIM gives $q(\mathrm{~N})$ for $\left[\mathrm{C}_{4} \mathrm{C}_{1} \mathrm{Im}\right]^{+}$and $\left[\mathrm{X}(\mathrm{CN})_{y}\right]^{-}$ to be identical (for all four anions). For NBO, $q(\mathrm{~N})$ is the same for $\left[\mathrm{C}_{4} \mathrm{C}_{1} \mathrm{Im}\right]^{+},\left[\mathrm{C}(\mathrm{CN})_{3}\right]^{-}$, and $\left[\mathrm{B}(\mathrm{CN})_{4}\right]^{-}$. By contrast, ChelpG for all four ILs finds $q(\mathrm{~N})$ for $\left[\mathrm{X}(\mathrm{CN})_{y}\right]^{-}$to be negative $(-0.5 e$ to $-0.7 e)$ and $q(\mathrm{~N})$ in $\left[\mathrm{C}_{4} \mathrm{C}_{1} \mathrm{Im}\right]^{+}$to be positive $(+0.1 e$ to $+0.2 e)$. The difference in $q(\mathrm{~N})$ between $\left[\mathrm{X}(\mathrm{CN})_{y}\right]^{-}$and $\left[\mathrm{C}_{4} \mathrm{C}_{1} \mathrm{Im}\right]^{+}, \sim 0.7 e$, is significant and agrees with the experimental $E_{\mathrm{B}}$ values [unlike for $q(\mathrm{~N})$ from both AIM and NBO]. Therefore, ChelpG was the only method to consistently assign a significantly more positive charge for $\left[\mathrm{C}_{4} \mathrm{C}_{1} \mathrm{Im}\right]^{+}$nitrogen atoms compared with the cyano nitrogen atoms in $\left[\mathrm{X}(\mathrm{CN})_{y}\right]^{-}$. Overall, ChelpG is the method with the best correlation to experiment.

Taking into account both the experimental ( $E_{\mathrm{B}}$ values) and computational data (ChelpG) for $q(\mathrm{~N})$, the relative ordering of charge on the nitrogen atom for these cations and anions is found to be (from most to least negatively charged) $[\mathrm{SCN}]^{-} \approx\left[\mathrm{N}(\mathrm{CN})_{2}\right]^{-} \approx\left[\mathrm{NTf}_{2}\right]^{-}<\left[\mathrm{C}(\mathrm{CN})_{3}\right]^{-} \approx\left[\mathrm{B}(\mathrm{CN})_{4}\right]^{-}$ $<\left[\mathrm{C}_{n} \mathrm{C}_{1} \mathrm{Im}\right]^{+} \approx\left[\mathrm{N}_{a, b, c, 0}\right]^{+}<\left[\mathrm{NO}_{3}\right]^{-}$. These values suggest that nitrogen carries a significant negative charge in all the anions studied (except $\left[\mathrm{NO}_{3}\right]^{-}$) and a slight positive charge in the cations studied. The effect of the counterion on $q(\mathrm{~N})$ was found to be negligible for $q(\mathrm{~N})$ for $\left[\mathrm{C}_{n} \mathrm{C}_{1} \mathrm{Im}\right][\mathrm{A}] \mathrm{ILs}$, based on both $E_{\mathrm{NEXAFS}}$ values and calculated $q(\mathrm{~N})$ for all methods. The lack of a counterion effect is consistent with previous results and shows that intramolecular covalent interactions are the main factor determining $q(\mathrm{~N})$ for imidazolium-based ILs. $^{21}$

\section{CONCLUSIONS}

The focus of this paper is on understanding atomic charge assignment methods for ILs. N 1s XP spectra and N 1s NEXAFS spectra have been presented for a range of nine ILs. Computational data on $q(\mathrm{~N})$ in the GP and within an IL(SMD) environment employing AIM, NBO, and ChelpG charge assignment methods have been determined for these ILs.

We have demonstrated that XPS is a superior technique to NEXAFS spectroscopy for identifying initial state effects, and therefore $q(\mathrm{~A})$, for a structurally diverse dataset of ILs. The final state effects observed using NEXAFS spectroscopy for a structurally diverse dataset of ionic liquids precludes its use for drawing conclusions on $q(\mathrm{~A})$. However, NEXAFS spectroscopy can provide excellent insight into $q(\mathrm{~A})$ when the IL dataset studied contains only structurally very similar ions.

ChelpG was determined to be the most suitable method for determining $q(\mathrm{~A})$ in ILs, based on the good agreement of $q(\mathrm{~A})$ with XPS $E_{\mathrm{B}}$ data for both nitrogen in the current study and sulfur in a previous study. ${ }^{21}$ The excellent agreement between ChelpG $q(\mathrm{~A})$ and XPS experimental data justifies the physical interpretation we make using ChelpG $q(\mathrm{~A})$. Both AIM and NBO $q(\mathrm{~A})$ assignment methods failed to correlate well with experimental $E_{\mathrm{B}}$. ChelpG showed more significant conformational differences of up to $0.3 e$; therefore, we advise that small differences in ChelpG charges $(<0.3 e)$ should be interpreted with care.

The overall charge $q(\mathrm{~N})$ assigned to the two nitrogen atoms on the dialkylimidazolium cation are slightly positive using the ChelpG method; by contrast, both the AIM and NBO methods give negative $q(\mathrm{~N})$. Based on our matches to experimental data, we tentatively conclude that the nitrogen atoms in the dialkylimidazolium cation are slightly positively charged. Furthermore, dialkylimidazolium $q(\mathrm{~N})$ do not depend on the counterion identity, based on results from both $q(\mathrm{~N})$ and NEXAFS spectroscopy.

\section{SUPPLEMENTARY MATERIAL}

See supplementary material for experimental methods and core-level X-ray photoelectron spectra, computational methods and results for IL(SMD) and conformers.

\section{ACKNOWLEDGMENTS}

K.R.J.L. acknowledges Imperial College London for the award of a Junior Research Fellowship and the Royal Society for the award of a University Research Fellowship. The authors are grateful to Jacek Osiecki and Karsten Handrup (MAXlab, Sweden) for assistance with the experiments. The authors 
acknowledge the EPSRC for the award of a studentship. The authors thank MAX-lab for awarding beamtime on I311.

${ }^{1}$ J. P. Hallett and T. Welton, Chem. Rev. 111, 3508-3576 (2011).

${ }^{2}$ M. Armand, F. Endres, D. R. MacFarlane, H. Ohno, and B. Scrosati, Nat. Mater. 8, 621-629 (2009).

${ }^{3}$ D. R. MacFarlane, M. Forsyth, P. C. Howlett, M. Kar, S. Passerini, J. M. Pringle, H. Ohno, M. Watanabe, F. Yan, W. J. Zheng, S. G. Zhang, and J. Zhang, Nat. Rev. Mater. 1, 15005 (2016).

${ }^{4}$ D. R. MacFarlane, N. Tachikawa, M. Forsyth, J. M. Pringle, P. C. Howlett, G. D. Elliott, J. H. Davis, M. Watanabe, P. Simon, and C. A. Angell, Energy Environ. Sci. 7, 232-250 (2014).

${ }^{5}$ P. Hapiot and C. Lagrost, Chem. Rev. 108, 2238-2264 (2008).

${ }^{6}$ Y. F. Hu, Z. C. Liu, C. M. Xu, and X. M. Zhang, Chem. Soc. Rev. 40, 3802-3823 (2011).

${ }^{7}$ X. P. Zhang, X. C. Zhang, H. F. Dong, Z. J. Zhao, S. J. Zhang, and Y. Huang, Energy Environ. Sci. 5, 6668-6681 (2012).

${ }^{8}$ X. Q. Sun, H. M. Luo, and S. Dai, Chem. Rev. 112, 2100-2128 (2012).

${ }^{9}$ H. L. Li and M. N. Kobrak, J. Chem. Phys. 131, 194507 (2009).

${ }^{10}$ M. Kohagen, M. Brehm, J. Thar, W. Zhao, F. Müller-Plathe, and B. Kirchner, J. Phys. Chem. B 115, 693-702 (2011).

${ }^{11}$ A. R. Zolghadr, M. H. Ghatee, and F. Moosavi, Chem. Phys. 475, 23-31 (2016).

${ }^{12}$ R. Ishizuka and N. Matubayasi, J. Chem. Theory Comput. 12, 804-811 (2016).

${ }^{13}$ G. Garcia, M. Atilhan, and S. Aparicio, J. Mol. Liq. 211, 506-514 (2015).

${ }^{14}$ L. K. Scarbath-Evers, P. A. Hunt, B. Kirchner, D. R. MacFarlane, and S. Zahn, Phys. Chem. Chem. Phys. 17, 20205-20216 (2015).

${ }^{15}$ F. Dommert, K. Wendler, R. Berger, L. Delle Site, and C. Holm, ChemPhysChem 13, 1625-1637 (2012).

${ }^{16}$ R. M. Lynden-Bell and T. G. A. Youngs, J. Phys.: Condens. Matter 21, 424120 (2009).

${ }^{17}$ S. T. Keaveney, J. B. Harper, and A. K. Croft, RSC Adv. 5, 35709-35729 (2015).

${ }^{18}$ R. F. W. Bader, Acc. Chem. Res. 18, 9-15 (1985).

${ }^{19}$ R. F. W. Bader, Chem. Rev. 91, 893-928 (1991).

${ }^{20}$ P. Matczak, Computation 4(1), 3 (2016).

${ }^{21}$ R. M. Fogarty, R. Rowe, R. P. Matthews, M. T. Clough, C. R. Ashworth, A. Brandt, P. J. Corbett, R. G. Palgrave, E. F. Smith, R. A. Bourne, T. W. Chamberlain, P. B. J. Thompson, P. A. Hunt, and K. R. J. Lovelock, Faraday Discuss. 206, 183-201 (2018).

${ }^{22} \mathrm{~F}$. Jensen, Introduction to Computational Chemistry (John Wiley \& Sons Ltd, West Sussex, 2007).

${ }^{23}$ A. E. Reed, R. B. Weinstock, and F. Weinhold, J. Chem. Phys. 83, 735-746 (1985).

${ }^{24}$ A. E. Reed, L. A. Curtiss, and F. Weinhold, Chem. Rev. 88, 899-926 (1988).

${ }^{25}$ C. M. Breneman and K. B. Wiberg, J. Comput. Chem. 11, 361-373 (1990).

${ }^{26}$ C. I. Bayly, P. Cieplak, W. D. Cornell, and P. A. Kollman, J. Phys. Chem. 97, 10269-10280 (1993).

${ }^{27}$ E. Sigfridsson and U. Ryde, J. Comput. Chem. 19, 377-395 (1998).

${ }^{28}$ P. A. Hunt, B. Kirchner, and T. Welton, Chem. - Eur. J. 12, 6762-6775 (2006).

${ }^{29}$ M. S. Shaik, M. Devereux, and P. L. A. Popelier, Mol. Phys. 106, 1495-1510 (2008).

${ }^{30}$ A. J. Misquitta, A. J. Stone, and S. L. Price, J. Chem. Theory Comput. 4, 19-32 (2008).

${ }^{31}$ G. A. Cisneros, M. Karttunen, P. Y. Ren, and C. Sagui, Chem. Rev. 114, 779-814 (2014).

${ }^{32}$ N. Mårtensson and A. Nilsson, J. Electron Spectrosc. Relat. Phenom. 75, 209-223 (1995).

${ }^{33}$ W. F. Egelhoff, Surf. Sci. Rep. 6, 253-415 (1987).

${ }^{34}$ I. J. Villar-Garcia, E. F. Smith, A. W. Taylor, F. L. Qiu, K. R. J. Lovelock, R. G. Jones, and P. Licence, Phys. Chem. Chem. Phys. 13, 2797-2808 (2011).

${ }^{35}$ C. Sleigh, A. P. Pijpers, A. Jaspers, B. Coussens, and R. J. Meier, J. Electron Spectrosc. Relat. Phenom. 77, 41-57 (1996).

${ }^{36}$ B. J. Lindberg, K. Hamrin, G. Johansson, U. Gelius, A. Fahlman, C. Nordling, and K. Siegbahn, Phys. Scr. 1, 286-298 (1970).

${ }^{37}$ U. Gelius, P. F. Heden, J. Hedman, B. J. Lindberg, R. Marine, R. Nordberg, C. Nordling, and K. Siegbahn, Phys. Scr. 2, 70-80 (1970).

${ }^{38}$ D. N. Hendrickson, J. M. Hollander, and W. L. Jolly, Inorg. Chem. 8, 2642-2647 (1969).

${ }^{39}$ J. M. Hollander and W. L. Jolly, Acc. Chem. Res. 3, 193-200 (1970).
${ }^{40}$ L. E. Cox, D. M. Hercules, and J. J. Jack, J. Am. Chem. Soc. 94, 6575-6578 (1972).

${ }^{41}$ T. Cremer, C. Kolbeck, K. R. J. Lovelock, N. Paape, R. Wölfel, P. S. Schulz, P. Wasserscheid, H. Weber, J. Thar, B. Kirchner, F. Maier, and H. P. Steinrück, Chem. - Eur. J. 16, 9018-9033 (2010).

${ }^{42}$ K. R. J. Lovelock, I. J. Villar-Garcia, F. Maier, H. P. Steinrück, and P. Licence, Chem. Rev. 110, 5158-5190 (2010).

${ }^{43}$ S. Men, K. R. J. Lovelock, and P. Licence, Phys. Chem. Chem. Phys. 13, 15244-15255 (2011).

${ }^{44}$ B. B. Hurisso, K. R. J. Lovelock, and P. Licence, Phys. Chem. Chem. Phys. 13, 17737-17748 (2011).

${ }^{45}$ I. J. Villar-Garcia, K. R. J. Lovelock, S. Men, and P. Licence, Chem. Sci. 5, 2573-2579 (2014).

${ }^{46}$ R. K. Blundell and P. Licence, Phys. Chem. Chem. Phys. 16, 15278-15288 (2014).

${ }^{47}$ R. K. Blundell and P. Licence, Chem. Commun. 50, 12080-12083 (2014).

${ }^{48}$ S. Men, D. S. Mitchell, K. R. J. Lovelock, and P. Licence, ChemPhysChem 16, 2211-2218 (2015).

${ }^{49}$ A. R. Santos, R. K. Blundell, and P. Licence, Phys. Chem. Chem. Phys. 17, 11839-11847 (2015).

${ }^{50}$ A. Vairavamurthy, Spectrochim. Acta, Part A 54, 2009-2017 (1998).

${ }^{51}$ F. Zhang, P. Wang, J. Koberstein, S. Khalid, and S. W. Chan, Surf. Sci. 563, 74-82 (2004).

${ }^{52}$ H. Dau, P. Liebisch, and M. Haumann, Anal. Bioanal. Chem. 376, 562-583 (2003).

${ }^{53}$ N. Weiher, E. Bus, L. Delannoy, C. Louis, D. E. Ramaker, J. T. Miller, and J. A. van Bokhoven, J. Catal. 240, 100-107 (2006).

${ }^{54}$ J. D. Grunwaldt, M. Caravati, and A. Baiker, J. Phys. Chem. B 110, 25586-25589 (2006).

${ }^{55}$ F. Jalilehvand, Chem. Soc. Rev. 35, 1256-1268 (2006).

${ }^{56}$ J. Rigby and E. I. Izgorodina, Phys. Chem. Chem. Phys. 15, 1632-1646 (2013).

${ }^{57}$ I. J. Villar-Garcia, S. Fearn, G. F. De Gregorio, N. L. Ismail, F. J. V. Gschwend, A. J. S. McIntosh, and K. R. J. Lovelock, Chem. Sci. 5, 4404-4418 (2014).

${ }^{58}$ T. Vander Hoogerstraete and K. Binnemans, Green Chem. 16, 1594-1606 (2014).

${ }^{59}$ G. F. De Gregorio, C. C. Weber, J. Grasvik, T. Welton, A. Brandt, and J. P. Hallett, Green Chem. 18, 5456-5465 (2016).

${ }^{60}$ C. Kolbeck, M. Killian, F. Maier, N. Paape, P. Wasserscheid, and H. P. Steinrück, Langmuir 24, 9500-9507 (2008).

${ }^{61}$ R. Nyholm, J. N. Andersen, U. Johansson, B. N. Jensen, and I. Lindau, Nucl. Instrum. Methods Phys. Res., Sect. A 467, 520-524 (2001).

${ }^{62}$ A. D. Becke, Phys. Rev. A 38, 3098-3100 (1988).

${ }^{63}$ C. T. Lee, W. T. Yang, and R. G. Parr, Phys. Rev. B 37, 785-789 (1988).

${ }^{64}$ A. D. Becke, J. Chem. Phys. 98, 5648-5652 (1993).

${ }^{65}$ R. H. Hertwig and W. Koch, Chem. Phys. Lett. 268, 345-351 (1997).

${ }^{66}$ M. J. Frisch, G. W. Trucks, H. B. Schlegel, G. E. Scuseria, M. A. Robb, J. R. Cheeseman, G. Scalmani, V. Barone, B. Mennucci, G. A. Petersson, H. Nakatsuji, M. Caricato, X. Li, H. P. Hratchian, A. F. Izmaylov, J. Bloino, G. Zheng, J. L. Sonnenberg, M. Hada, M. Ehara, K. Toyota, R. Fukuda, J. Hasegawa, M. Ishida, T. Nakajima, Y. Honda, O. Kitao, H. Nakai, T. Vreven, J. J. A. Montgomery, J. E. Peralta, F. Ogliaro, M. Bearpark, J. J. Heyd, E. Brothers, K. N. Kudin, V. N. Staroverov, R. Kobayashi, J. Normand, K. Raghavachari, A. Rendell, J. C. Burant, S. S. Iyengar, J. Tomasi, M. Cossi, N. Rega, J. M. Millam, M. Klene, J. E. Knox, J. B. Cross, V. Bakken, C. Adamo, J. Jaramillo, R. Gomperts, R. E. Stratmann, O. Yazyev, A. J. Austin, R. Cammi, C. Pomelli, J. W. Ochterski, R. L. Martin, K. Morokuma, V. G. Zakrzewski, G. A. Voth, P. Salvador, J. J. Dannenberg, S. Dapprich, A. D. Daniels, Ö. Farkas, J. B. Foresman, J. V. Ortiz, J. Cioslowski, and D. J. Fox, Gaussian 09, Revision D.01, Gaussian, Inc., Wallingford CT, 2009.

${ }^{67}$ S. Grimme, J. Antony, S. Ehrlich, and H. Krieg, J. Chem. Phys. 132, 154104 (2010).

${ }^{68}$ S. Grimme, S. Ehrlich, and L. Goerigk, J. Comput. Chem. 32, 1456-1465 (2011).

${ }^{69}$ A. V. Marenich, C. J. Cramer, and D. G. Truhlar, J. Phys. Chem. B 113, 6378-6396 (2009).

${ }^{70}$ V. S. Bernales, A. V. Marenich, R. Contreras, C. J. Cramer, and D. G. Truhlar, J. Phys. Chem. B 116, 9122-9129 (2012).

${ }^{71}$ T. A. Keith, AIMAll, TK Gristmill Software, Overland Park KS, 2014.

${ }^{72}$ E. D. Glendening, J. K. Badenhoop, A. E. Reed, J. E. Carpenter, J. A. Bohmann, C. M. Morales, and F. Weinhold, NBO 5.0 Program, 2001. 
${ }^{73}$ J. K. Chang, M. T. Lee, W. T. Tsai, M. J. Deng, H. F. Cheng, and I. W. Sun, Langmuir 25, 11955-11960 (2009).

${ }^{74}$ R. M. Fogarty, R. P. Matthews, M. T. Clough, C. R. Ashworth, A. BrandtTalbot, P. J. Corbett, R. G. Palgrave, R. A. Bourne, T. W. Chamberlain, T. Vander Hoogerstraete, P. B. J. Thompson, P. A. Hunt, N. A. Besley, and K. R. J. Lovelock, Phys. Chem. Chem. Phys. 19, 31156-31167 (2017).

${ }^{75}$ F. Rodrigues, D. Galante, G. M. do Nascimento, and P. S. Santos, J. Phys. Chem. B 116, 1491-1498 (2012).

${ }^{76}$ C. Ehlert, M. Holzweber, A. Lippitz, W. E. S. Unger, and P. Saalfrank, Phys. Chem. Chem. Phys. 18, 8654-8661 (2016).
${ }^{77}$ Y. Horikawa, T. Tokushima, O. Takahashi, H. Hoke, and T. Takamuku, J. Phys. Chem. B 120, 7480-7487 (2016).

${ }^{78}$ D. Weingarth, I. Czekaj, Z. F. Fei, A. Foelske-Schmitz, P. J. Dyson, A. Wokaun, and R. Kotz, J. Electrochem. Soc. 159, H611-H615 (2012).

${ }^{79}$ J. K. Chang, M. T. Lee, C. W. Cheng, W. T. Tsai, M. J. Deng, Y. C. Hsieh, and I. W. Sun, J. Mater. Chem. 19, 3732-3738 (2009).

${ }^{80}$ O. Höfft, S. Bahr, M. Himmerlich, S. Krischok, J. A. Schaefer, and V. Kempter, Langmuir 22, 7120-7123 (2006).

${ }^{81}$ S. Men and J. Jiang, Chem. Phys. Lett. 677, 60-64 (2017). 